\title{
Autoantibodies to nervous tissue structures are associated with autonomic neuropathy in Type 1 (insulin-dependent) diabetes mellitus
}

\author{
M.M.Zanone ${ }^{1}$, M.Peakman ${ }^{2}$, T.Purewal ${ }^{1}$, P.J. Watkins ${ }^{1}$, D. Vergani ${ }^{2}$ \\ ${ }^{1}$ Diabetic Department, King's College Hospital, London, UK \\ ${ }^{2}$ Immunology Department, King's College School of Medicine and Dentistry, London, UK
}

Summary. There is evidence that the immune system may play a role in the pathogenesis of autonomic neuropathy in Type 1 (insulin-dependent) diabetes mellitus. In the present study, we investigated the presence of autoantibodies to sympathetic and parasympathetic nervous structures and their correlation with other conventional autoantibodies in wellcharacterised diabetic populations, with or without diabetic neuropathy, and normal subjects. An indirect immunofluorescent complement-fixation technique was used, with monkey adrenal gland, rabbit cervical ganglia and vagus nerve as substrates. Of the patients with symptomatic autonomic neuropathy $33 \%$ were positive for at least one autoantibody (20\% anti-sympathetic ganglia, $10 \%$ anti-vagus nerve and $13 \%$ anti-adrenal medulla). The frequency of having one or more antibodies to nervous tissues and the prevalence of anti-cervical ganglia antibodies were significantly higher in the neuropathic patients than in the diabetic control subjects with disease of similar duration and in the normal subjects $(p<0.05)$. Of the patients without complications with diabetes of shorter duration $33 \%$ were also positive for at least one autoantibody (13\% anti-ganglia, $13 \%$ anti-vagus nerve and $13 \%$ anti-adrenal medulla). No correlation was found with other tissue autoantibodies, including islet cell antibodies. Our data indicate that nervous tissue autoantibodies are associated with symptomatic autonomic neuropathy. Anti-sympathetic ganglia and anti-vagus nerve antibodies seem to be more disease-specific. Patients with diabetes of shorter duration who were positive for these autoantibodies may represent pre-neuropathic patients.

Key words: Diabetic neuropathy, autonomic neuropathy, Type 1 (insulin-dependent) diabetes mellitus, nervous tissue autoantibodies, islet cell antibodies.
The pathogenesis of diabetic autonomic neuropathy is not known but there is evidence to suggest that immunological factors play a role in its development. Inflammatory infiltrates composed of lymphocytes, macrophages and occasional plasma cells are seen in autonomic ganglia and in autonomic nerve bundles in post-mortem specimens from diabetic patients with severe autonomic neuropathy [1]. In a group of similar patients, we documented an increased level of circulating activated T lymphocytes [2], suggesting a role for the cellular immune system in the pathogenesis of this complication. Levels of activated Tlymphocytes are raised in newly-diagnosed Type 1 (insulindependent) diabetic patients, but tend to return to normal within 2-3 years. Their persistence or, possibly, reappearance in diabetic neuropathy may represent continuing immune activation against targets other than the pancreatic islet beta cells. We also described the association of severe autonomic neuropathy with iritis [3], which is thought to be an immune-complex-mediated disorder [4], and with elevated levels of circulating immune complexes and com- plement activation products, showing that complementfixing antigen-antibody complexes characterise this diabetic complication [5]. Whilst complement activation indicates ongoing inflammation tissue damage, the nature of the antigen within the complexes is not known.

In recent studies, autoantibodies to autonomic nervous tissue components in sympathetic ganglia, adrenal medulla and vagus nerve were detected in the blood of diabetic patients [6], raising the possibility that they have a role in the development of neuropathy. In these studies, autoantibodies to autonomic nervous tissues tended to have a higher prevalence near to diagnosis of Type 1 diabetes but were not clearly related to the presence of neuropathy. In one report, a history of neuropathic symptoms was not available and, on formal examination, only one abnormal cardiovascular test was considered diagnostic of neuropathy [7], whilst in another study the presence of abnormal autonomic function was examined retrospectively [8].

We have previously studied, and therefore could recruit, patients with well-documented asymptomatic or 
Table 1. Clinical details of subjects

\begin{tabular}{lllcc}
\hline & $\begin{array}{l}\text { Type 1 diabetic patients } \\
\text { with neuropathy } \\
(n=37)\end{array}$ & $\begin{array}{l}\text { Long-duration Type 1 } \\
\text { diabetic control subjects } \\
(n=25)\end{array}$ & $\begin{array}{l}\text { Short-duration Type 1 } \\
\text { diabetic control subjects } \\
(n=15)\end{array}$ & $\begin{array}{l}\text { Normal control subjects } \\
(n=27)\end{array}$ \\
\hline Age (years) ${ }^{\mathrm{a}}$ & $43.2 \pm 11.1$ & $41.8 \pm 12.4$ & $28.1 \pm 9$ & $44.5 \pm 11$ \\
Sex (M:F) & $14: 23$ & $13: 12$ & $10: 5$ & $14: 13$ \\
Duration of diabetes (years) & $29.8 \pm 10.4$ & $25.6 \pm 9.1$ & $6.9 \pm 3.9$ & - \\
Subjects with: & & & & - \\
Iritis & 8 & 0 & 0 & - \\
Charcot joints & 10 & 0 & 0 & - \\
History of foot ulcer & 24 & 0 & 0 & - \\
Absent ankle jerks & 34 & 0 & 0 & - \\
Proteinuria: intermittent & 11 & 0 & 0 & - \\
Retinopathy: background & 15 & 0 & 0 & - \\
$\quad$ proliferative & 28 & 2 & 0 & - \\
HbA ${ }_{1}{ }^{2}$ & $12.3 \pm 2.4$ & 0 & $10 \pm 1.8$ & \\
\hline
\end{tabular}

${ }^{a}$ Data are shown as mean $\pm \mathrm{SD}$

Table 2. Autonomic symptoms of Type 1 diabetic patients with symptomatic autonomic neuropathy $(n=30)$

\begin{tabular}{lcc}
\hline & Total & $\%$ \\
\hline Gustatory sweating & 22 & 73 \\
Diarrhoea & 16 & 53 \\
Gastroparesis & 3 & 10 \\
Bladder paresis & 2 & 7 \\
Postural hypotension & 9 & 30 \\
Respiratory/cardiac arrest & 3 & 10 \\
\hline
\end{tabular}

symptomatic autonomic neuropathy $[1-3,5]$. The aim of the present study was to explore the relationship between autoantibodies to sympathetic (adrenal medulla and cervical ganglia) and parasympathetic (vagus nerve) nervous structures and diabetic autonomic neuropathy.

\section{Subjects, materials and methods}

\section{Subjects}

Sera for the study were drawn from patients with Type 1 diabetes attending the Diabetic Clinic at King's College Hospital, after having obtained informed consent. Ethical permission for this study was obtained from the Ethical Committee of Camberwell Health Authority.

These patients were well characterized clinically and have been classified into three groups. Group 1 comprised 37 Type 1 diabetic patients with a long duration of diabetes (mean age $43.1 \pm 11.1$ years, mean duration of disease $29.8 \pm 10.4$ years, range $10-52$ years), of whom 30 had symptomatic autonomic and somatic neuropathy (subgroup A) and 7 were without autonomic symptoms (subgroup B). All had abnormal autonomic function tests and other diabetic complications were similar in subgroup A and B (Table 1).

The following symptoms of autonomic neuropathy were recorded (Table 2): diabetic diarrhoea, vomiting due to gastroparesis, gustatory sweating, bladder paresis and postural hypotension, as defined previously [3]. Eight of these patients had also had one or more episodes of iritis, diagnosed by an ophthalmologist and treated with topical steroids; ten had Charcot joints, recorded radiologically; three patients with gastroparesis were shown to have grossly delayed gastric emptying by radioisotopic studies.
Group 2 comprised 25 Type 1 diabetic patients, matched for age $(41.8 \pm 12.4$ years) and duration of diabetes $(25.6 \pm 9.1$ years, range 16-46 years), without evidence of either autonomic or somatic neuropathy. They had normal cardiovascular tests and normal sensory thresholds; only two had very mild background retinopathy but no other diabetic complications.

Group 3 comprised 15 Type 1 diabetic control subjects with a shorter duration of disease ( $6.9 \pm 3.9$ years, range $1-12$ years) with no complications and with normal autonomic function tests.

A group of 27 healthy, age ( $44.5 \pm 11$ years) and sex-matched control subjects, were also studied.

In all groups, the presence of thyroid dysfunction was also evaluated clinically and, when indicated, with the measurement of thyroid stimulating hormone. Metabolic control was assessed by measurement of $\mathrm{HbA}_{1}$ (REP system; Helena Instruments, Beaumont, Tx., USA). $\mathrm{HbA}_{1}$ levels were higher in the autonomic neuropathy group than those in the uncomplicated Type 1 diabetic patients (Table 1).

\section{Assessment of neuropathy}

Autonomic neuropathy (small-fibre neuropathy) was assessed by performing standard cardiovascular tests on an automated system integrated with a personal computer. The tests consist of: heart rate variability on six maximal breaths per min (abnormal $<10$ ); heart rate increase on standing at $15 \mathrm{~s}$ (abnormal $<12$ ); Valsalva ratio, (abnormal <1.2); postural systolic blood pressure decrease on standing (abnormal $>30 \mathrm{~mm} \mathrm{Hg}$ ), as defined previously [9].

Peripheral somatic neuropathy (large-fibre neuropathy) was assessed by clinical and neurological examination, including ankle reflexes, presence of neuropathic foot ulcers past or present, together with recording the vibration sensory threshold at the tip of the great toe, using a biothesiometer (abnormal $>10 \mathrm{~V}$ ). Thermal sensory thresholds (small-fibre neuropathy) were recorded on the dorsum of the feet, with a Medelec stimulator (abnormal $>2^{\circ} \mathrm{C}$ ).

The presence of other diabetic complications was evaluated with the detection of proteinuria on albustix testing, measurement of serum creatinine and by ophthalmoscopy.

Details of tests of autonomic function and peripheral sensory thresholds are shown in Table 3.

\section{Assay for complement-fixing nervous tissue antibodies}

An indirect immunofluorescent complement-fixation technique was used in all three assays, with monkey adrenal gland (INOVA, Birmingham, UK), rabbit vagus nerve and cervical ganglia as sub- 
Table 3. Autonomic function and peripheral sensory nerve thresholds

\begin{tabular}{lccc}
\hline & $\begin{array}{l}\text { Type 1 diabetic patients } \\
\text { with neuropathy } \\
(n=37)\end{array}$ & $\begin{array}{l}\text { Long-duration Type 1 } \\
\text { diabetic control subjects } \\
(n=25)\end{array}$ & $\begin{array}{l}\text { Short-duration Type 1 } \\
\text { diabetic control subjects } \\
(n=15)\end{array}$ \\
\hline HRV (abnormal $<10)^{\mathrm{a}}$ & $3.9 \pm 1.7$ & $19.4 \pm 5.5$ & $20.4 \pm 5.7$ \\
Valsalva (abnormal $<1.2)^{\mathrm{a}}$ & $1.2 \pm 0.23$ & $1.7 \pm 0.3$ & $2.1 \pm 0.3$ \\
Heart rate on standing $(\text { abnormal }<12)^{\mathrm{a}}$ & $7.1 \pm 5.2$ & $21.2 \pm 6.9$ & $28.4 \pm 6.7$ \\
Vibration threshold $(\text { abnormal }>10 \mathrm{~V})^{\mathrm{a}}$ & $25.5 \pm 12.8$ & $7.8 \pm 4.5$ & $5.8 \pm 2.5$ \\
Subjects with: & & 0 & 0 \\
Abnormal thermal thresholds $\left(>2^{\circ} \mathrm{C}\right)$ & $36 / 37$ & 0 & 0 \\
Systolic blood pressure drop $>30 \mathrm{~mm} \mathrm{Hg}$ & $9 / 37$ & & \\
\hline
\end{tabular}

${ }^{\circledR}$ Data are shown as mean \pm SD. HRV, Heart rate variability

strates. Vagus nerve and sympathetic chain cervical ganglia were isolated from an adult New Zealand white rabbit, snap frozen and stored in liquid nitrogen until use.

Cryostat sections ( $5 \mu \mathrm{m}$ thick) of vagus nerve and ganglia were allowed to air dry and then fixed in acetone for 5 min. Sections were incubated with $50 \mu \mathrm{l}$ of undiluted test serum for $30 \mathrm{~min}$ at room temperature. Slides were then washed in phosphate-buffered saline (PBS; $140 \mathrm{mmol} / / \mathrm{NaCl}, 3 \mathrm{mmol} / \mathrm{KCl}, 8 \mathrm{mmol} / \mathrm{Na} \mathrm{H}_{2} \mathrm{HPO}_{4}, 1 \mathrm{mmol} / 1$ $\mathrm{KH}_{2} \mathrm{PO}_{4}, \mathrm{pH} 7.2$ ) for 15 min and 50 ul of fresh normal human serum as a source of complement added at a 1:5 dilution in PBS. Following incubation for $30 \mathrm{~min}$ at $37^{\circ} \mathrm{C}$, slides were washed again as above and $50 \mu \mathrm{l}$ of fluorescein isothiocyanate conjugated (FITC) sheep antihuman C3c (Binding Site, Birmingham, UK) diluted 1:20 in PBS, was added and incubated for $30 \mathrm{~min}$ at room temperature. Slides were washed again, mounted in PBS-glycerol and examined under an ultraviolet microscope (Polyvar, Vienna, Austria). Slides were read independently by two observers (MZ and MP) unaware of clinical details. Positivity for all anti-autonomic tissue autoantibodies were confirmed by repeated measurement using substrate from a different animal and serum drawn on a different occasion.

\section{Assays for other organ-specific antibodies}

Islet cell antibodies (ICA) were detected by indirect immunofluorescence on cryostat sections of group 0 human pancreas as previously described [10].

Anti-thyroglobulin (anti-TG) and anti-thyroid microsomal (anti-TM) autoantibodies were detected by gelatin particle agglutination, using commercially available kits (Fujirebio, Tokyo, Japan). A titre of $1 / 400$ or more was considered a positive result.

\section{Statistical analysis}

The distribution of autoantibodies among the different clinical groups was compared using Fisher's exact test, with $p$ value less than 0.05 considered significant.

\section{Results}

\section{Vagus nerve immunofluorescence}

A positive pattern was defined by staining along nerve fibres in both longitudinal and transverse nerve sections for complement-fixing vagus nerve antibodies, as shown in Figure $1 \mathrm{~A}$ and B. These antibodies were detected in three $(10 \%)$ of the 30 patients with symptomatic autonomic neuropathy, of whom one (also ICA positive) had a higher fluorescence intensity (Table 4). One of these pa- tients has a history of iritis. Vagus nerve autoantibodies were also present in two (13\%) diabetic control subjects with short duration of disease (one ICA negative, who also had antibodies to sympathetic ganglia). The frequency of vagus nerve antibodies was not statistically different between any of the clinical groups.

\section{Sympathetic ganglia immunofluorescence}

A positive immunofluorescent pattern was defined by the detection of cytoplasmic staining of cell bodies of ganglion cells, as shown in Figure 1C. Six of $30(20 \%)$ diabetic subjects with symptomatic autonomic neuropathy (all but one ICA negative) were positive for complement-fixing sympathetic ganglia antibodies, of whom two were also positive for anti-vagus nerve antibodies (Table 4). This prevalence was significantly higher than in the diabetic control subjects with long disease duration $(0$ of 25$)$ $(p<0.05)$ and normal control subjects $(0$ of 27$)(p<0.05)$ and higher, but not significantly so, than in the diabetic control subjects with shorter duration of disease $(13 \%$, 2 of 15) (one ICA positive and one ICA negative).

\section{Adrenal medulla immunofluorescence}

A positive pattern was defined by fluorescence of the cytoplasm of adrenal medullary cells, as shown in Figure 1D. These antibodies were detected in four $(13 \%)$ patients with symptomatic autonomic neuropathy (all ICA negative), one of whom also had antibodies to sympathetic ganglia, in two (8\%) long-duration diabetic control subjects (both ICA negative), in two (13\%) shortduration control subjects (both ICA negative) and in one normal control subject ( $3 \%$ ) (Table 4 ). The frequency of adrenal medulla antibodies was not statistically different between any of the clinical groups.

Of the patients with symptomatic autonomic neuropathy $33 \%$ were positive for at least one autoantibody. This prevalence was significantly higher than in the longduration diabetic patients without complications $(8 \%)$ $(p<0.05)$ and normal control subjects $(3 \%)(p<0.005)$, who were positive for anti-adrenal medulla antibodies only. Of the patients without complications with a disease of shorter duration, $33 \%$ were found positive for at least one autoantibody. 

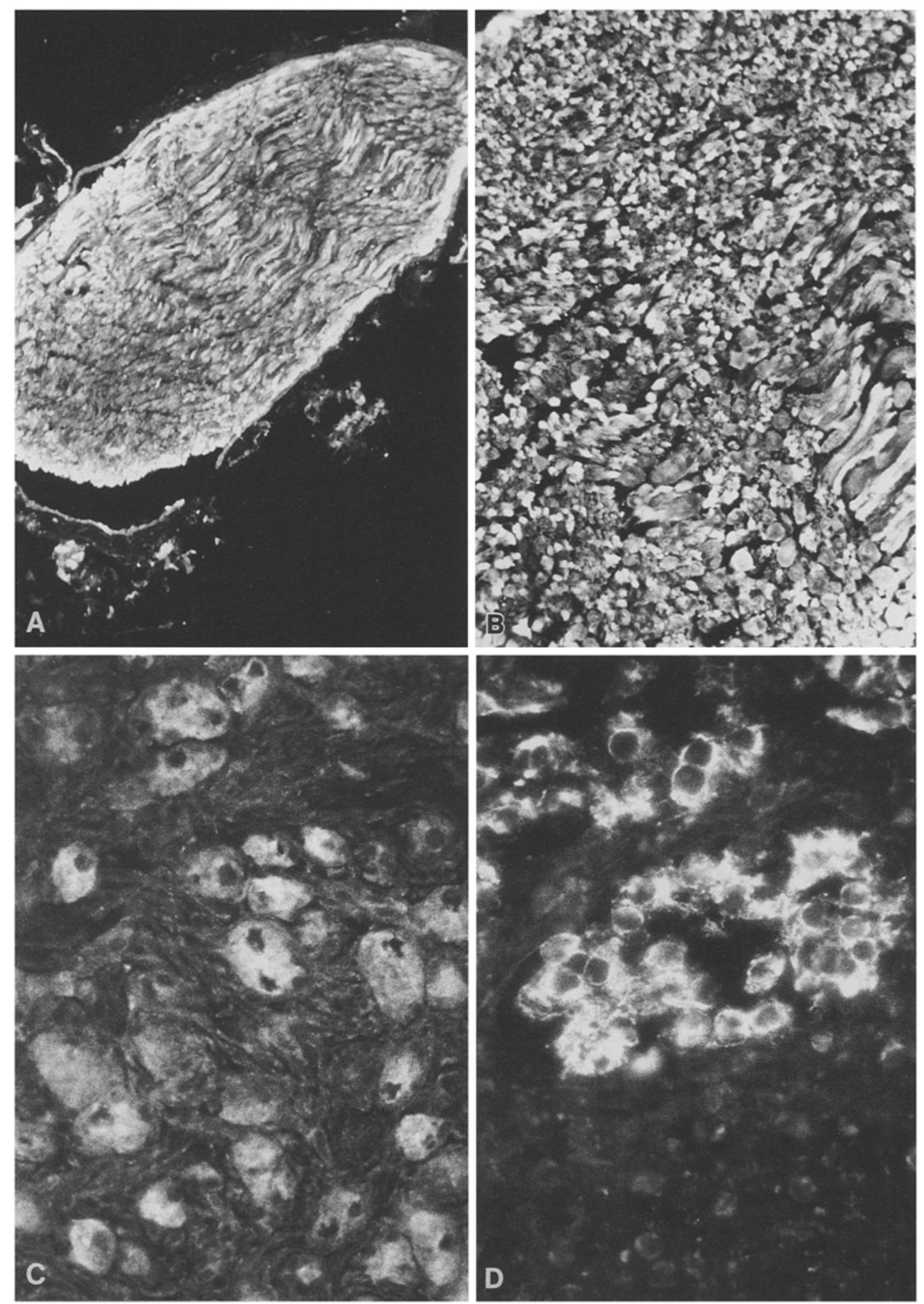

Fig. 1. A (Original magnification $\times 10$ ) and $\mathbf{B}$ (original magnification $\times 25$ ) show positive staining along longitudinal and transverse vagus nerve fibres

$\mathrm{C}$ (original magnification $\times 40$ ) shows cytoplasmic staining of cell bodies of sympathetic cervical ganglion cells

D (original magnification $\times 100$ ) shows cytoplasmic staining of adrenal medullary cells, contrasting with the unstained adrenal cortex

\section{Anti-thyroid antibodies}

Eleven $(37 \%)$ patients with symptomatic autonomic neuropathy, of whom six had hypothyroidism and three were anti-nervous tissue antibody positive (two with hypothyroidism), were positive for anti-TG or anti-TM antibodies or both (Table 4). Eight (32\%) long-duration diabetic patients without complications (two with hypothyroidism and one with anti-adrenal medulla antibodies), six ( $40 \%$ ) diabetic control subjects with shorter duration of disease (four with anti-nervous tissue antibodies) and six (four female and two male) $(22 \%)$ healthy control subjects were anti-TG or anti-TM (or both) antibody positive. None of the control subjects from group 3 or the normal control subjects had thyroid dysfunction.

\section{Discussion}

We have identified an association between the presence of autoantibodies to autonomic nervous tissue and Type 1 diabetic patients with symptomatic autonomic neuropathy. Of the autoantibodies studied, anti-sympathetic ganglia antibodies were significantly associated with 
Table 4. Autoantibody screening results

\begin{tabular}{|c|c|c|c|c|c|}
\hline & \multicolumn{2}{|c|}{$\begin{array}{l}\text { Type } 1 \text { diabetic subjects } \\
\text { with neuropathy }\end{array}$} & \multirow{2}{*}{$\begin{array}{l}\text { Long-duration Type } 1 \\
\text { diabetic control } \\
\text { subjects } \\
(n=25)\end{array}$} & \multirow{2}{*}{$\begin{array}{l}\text { Short-duration Type } 1 \\
\text { diabetic control } \\
\text { subjects } \\
(n=15)\end{array}$} & \multirow[t]{2}{*}{$\begin{array}{l}\text { Normal control } \\
\text { subjects }(n=27)\end{array}$} \\
\hline & $\begin{array}{l}\mathrm{A} \\
(n=30)\end{array}$ & $\begin{array}{l}\mathrm{B} \\
(n=7)\end{array}$ & & & \\
\hline Islet cell antibodies & 6 & 3 & 4 & 8 & 0 \\
\hline $\mathrm{CF}$-Vagus nerve $\mathrm{Ab}$ & $3(10 \%)$ & 0 & 0 & $2(13 \%)$ & 0 \\
\hline $\mathrm{CF}$-Cervical ganglia $\mathrm{Ab}$ & $6(20 \%)^{a}$ & 0 & 0 & $2(13 \%)$ & 0 \\
\hline CF-Adrenal medulla $\mathrm{Ab}$ & $4(13 \%)$ & 0 & $2(8 \%)$ & $2(13 \%)$ & $1(3 \%)$ \\
\hline Anti-TG Ab & 2 & 0 & 3 & 2 & 1 \\
\hline Anti-TM Ab & 11 & 0 & 9 & 5 & 6 \\
\hline
\end{tabular}

${ }^{a} p<0.05$ vs long-duration diabetic control subjects and vs normal control subjects. CF, complement fixing; Ab, antibodies; anti-TG, antithyroglobulin; anti-TM, anti-thyroid microsomal

symptomatic neuropathy. Both anti-sympathetic ganglia and anti-vagus nerve antibodies were absent in diabetic control subjects with disease of similar duration and normal control subjects. Anti-adrenal medulla antibodies tended to be found in all diabetic groups and in some healthy subjects. These autoantibodies are complementfixing and this characteristic, associated with our previous report [5] of complement breakdown products in patients with neuropathy, implicates complement activation as a possible mediator of nervous tissue damage. Whether these autoantibodies have a causative role or develop secondarily as a consequence of nerve damage due to other mechanisms is not known. If their production is induced by release of damaged nervous tissue, it remains a possibility that they may contribute to the progression and perpetuation of diabetic neuropathy.

Until the present study, there was no evidence linking autoantibodies to nervous structures and autonomic dysfunction in patients with Type 1 diabetes. This is the first study to analyse the prevalence of these antibodies in welldefined populations of patients with symptomatic and asymptomatic autonomic neuropathy assessed on formal testing. Our findings show that antibodies to sympathetic ganglia are present in a subgroup of patients with diabetes and symptomatic autonomic dysfunction and absent in patients without complications with disease of similar duration. In agreement with previous reports [11, 12], they are also present in some short-term patients without complications and perhaps - as Rabinowe et al. [12] have suggested - identify those patients destined to develop neuropathic symptoms. Whilst the cross-sectional nature of our study allows us to speculate about the possibility of predicting neuropathy and of a cause-effect relationship between these autoantibodies and diabetic neuropathy, we cannot exclude the possibility that the detection of antibodies to nervous tissue structures in patients with short duration of diabetes is due to their general tendency to develop immune abnormalities [13]. These questions are currently being addressed in a prospective study.

If indeed these autoantibodies are related to the development of neuropathy, their relatively low prevalence may have several explanations. Firstly, it is possible that these autoantibodies are bound to their target antigen in the nervous tissue, resulting in low or undetectable concentrations in the circulation. Secondly, these autoantibodies, when present, are found at low titre and the rela- tively insensitive technique of immunofluorescence that we have used may fail to detect them. Thirdly, these antibodies might behave like other organ-specific autoantibodies such as ICA [14] and anti-thyrotropin receptor antibody [15], which tend to decline after the target antigen has been irrevocably damaged. The notion that antibodies might appear early, to disappear when neuropathy is advanced, is indirectly supported by their being found in some patients without complications with short disease duration but in none of the diabetic control subjects with long disease duration.

Previous cross-sectional studies on antibodies to autonomic nervous structures indicated a higher prevalence of these antibodies in recent-onset Type 1 diabetic patients, who were ICA-positive, than in those with longterm diabetes. This can be interpreted as suggesting that antibodies to nervous tissue and ICA may have target antigens in common [16]. A candidate antigen might be glutamic acid decarboxylase (GAD) [17], an enzyme expressed in pancreatic islets as well as in peripheral nervous tissue and brain and target of autoantibodies in up to $75 \%$ of patients with recent-onset Type 1 diabetes [18]. GAD autoantibodies have also recently been described in association with diabetic neuropathy [18]. Thus, while GAD autoantibodies precede the development of diabetes and typically disappear during the following years, patients in whom these antibodies persist or reappear over many years (10-48 years after diagnosis) have been found by Kaufman et al. [18] to have peripheral and autonomic neuropathy. In that study, however, only a small number of patients was studied and non-human GAD was used as the antigenic target. This preliminary report of an association between GAD autoantibodies and neuropathy suggests continuing stimulation of the immune system by GAD in peripheral neurons and such observations need further investigation and confirmation. In our study we did not find any significant correlation between anti-nervous tissue autoantibodies and ICA or other conventional tissue autoantibodies, even in patients with short duration of diabetes. Our results indicate, therefore, that autoantibodies to nervous tissue may occur independently of the presence of other autoantibodies, notably ICA. This suggests that the target antigens are tissue-specific and that the presence of these autoantibodies does not simply reflect a tendency, seen in patients with Type 1 diabetes, to produce poly-specific autoantibodies [13]. 
Evidence for a role for the immune system in the development of diabetic neuropathies, especially autonomic neuropathy, is increasing and has come from several independent sources. Larger cross-sectional studies and, above all, longitudinal studies need to be conducted to clarify the role of these autoantibodies as markers of diabetic autonomic neuropathy, and in time the potential for immunosuppression, which has already been attempted [19], may need to be further examined.

Acknowledgements. This work has been supported by Regione Piemonte (Italy), Ricerca Sanitaria Finalizzata and the Medical Research Council, which also supports MMZ.

\section{References}

1. Duchen LW, Anjorin A, Watkins PJ, Mackay JD (1980) Pathology of autonomic neuropathy in diabetes mellitus. Ann Int Med 92: 301-303

2. Gilbey SG, Hussain MJ, Watkins PJ, Vergani D (1988) Cellmediated immunity and symptomatic diabetic autonomic neuropathy. Diabetic Med 5: $845-848$

3. Guy RJC, Richards F, Edmonds ME, Watkins PJ (1984) Diabetic autonomic neuropathy and iritis: an association suggesting an immunological cause? Br Med J 289:343-345

4. Dernouchamps JP, Vaerman JP, Michiels J, Masson PL (1977) Immune complexes in the aqueous humor and serum. Am J Ophthalmol 84: 24-31

5. Gilbey SG, Guy RJC, Vergani D, Watkins PJ (1986) Diabetes and autonomic neuropathy: an immunological association? Diabetic Med 3: 241-245

6. Rabinowe SL (1990) Immunology of diabetic and polyglandular neuropathy. Diab Metab Rev 6: 169-188

7. Sundkvist G, Lind P, Bergstrom B, Lilja B, Rabinowe SL (1991) Autonomic nerve antibodies and autonomic nerve function in type 1 and type 2 diabetic patients. J Intern Med 229:505-510

8. Rabinowe SL, Brown FM, Watts M, Smith AM (1990) Complement-fixing antibodies to sympathetic and parasympathetic tissues in IDDM. Diabetes Care 13: 1084-1088

9. Ewing DJ, Clarke BF (1982) Diagnosis and management of diabetic autonomic neuropathy. Br Med J 285: 916-919
10. Millward BA, Hussain MJ, Peakman M, Pyke DA, Leslie RDG, Vergani D (1988) Characterization of islet cell antibodies in insulin-dependent diabetes: evidence for IgG1 subclass restriction and polyclonality. Clin Exp Immunol 71:353-356

11. Brown FM, Kamalesh M, Sesh Adri MN, Rabinowe SL (1988) Anti-adrenal medullary antibodies in IDDM subjects and subjects at high risk of developing IDDM. Diabetes Care 11:30-33

12. Rabinowe SL, Brown FM, Watts M, Kadrofske MM, Vinik AI (1989) Anti-sympathetic ganglia antibodies and postural blood pressure in IDDM subjects of varying duration and patients at high risk of developing IDDM. Diabetes Care 12:1-6

13. Drell DW, Notkins AL (1987) Multiple immunological abnormalities in patients with type 1 (insulin-dependent) diabetes mellitus. Diabetologia 30: 132-143

14. Lendrum R, Walker GJ, Cudworth AG et al. (1975) Islet-cell antibodies in diabetes mellitus. Lancet II: 1273-1276

15. Peakman M, Hussain MJ, Cundy T, Vergani D (1989) Increased activated T-lymphocytes and normal thyrotropin receptor antibody levels in Graves disease in long-term remission. I Clin Lab Immunol 30: 1-5

16. Brown FM, Vinik AI, Ganda OP, Adri MNS, Rabinowe SL (1989) Different effects of duration on prevalence of anti-adrenal medullary and pancreatic islet cell antibodies in type 1 diabetes mellitus. Horm Metabol Res 21: 434-437

17. Baekkeskov S, Aanstoot HJ, Christgau S et al. (1990) Identification of the $64 \mathrm{~K}$ autoantigen in insulin-dependent diabetes as the GABA synthesizing enzyme glutamic acid decarboxylase. Nature (Lond) 347:151-156

18. Kaufman DL, Erlander MG, Salzer MC et al. (1992) Autoimmunity to two forms of glutamate decarboxylase in insulindependent diabetes mellitus. J Clin Invest 89:283-292

19. Goncavales E, Brown FM, Rabinowe SL (1990) Pilot study of immunosuppressive therapy in diabetic neuropathy associated with neuronal autoantibodies. Diabetes 39 [Suppl 1]: 778 (Abstract)

Received: 23 November 1992

and in revised form: 25 February 1993

Dr. M.M.Zanone

Diabetic Department

King's College Hospital

Denmark Hill

London SE5 9RS

UK 